\title{
PERILAKU MENCARI UMPAN BALIK MAHASISWA TAHAP SARJANA ANGKATAN PERTAMA DALAM PROSES PEMBELAJARAN DI FAKULTAS KEDOKTERAN UNIVERSITAS MALAHAYATI ANGKATAN 2020
}

\author{
Sri Maria Puji Lestari ${ }^{1}$, Supriyati ${ }^{2}$, Dessy Hermawan ${ }^{3}$, \\ Corryna Riva Destrado ${ }^{4}$
}

\begin{abstract}
${ }^{1}$ Departemen IImu Kesehatan, Fakultas Kedokteran, Universitas Malahayati
${ }^{2}$ Program Studi Psikologi, Fakultas Kedokteran, Universitas Malahayati

${ }^{3}$ Program Studi Keperawatan, Fakultas Kedokteran, Universitas Malahayati

${ }^{4}$ Program Studi Kedokteran, Fakultas Kedokteran, Universitas Malahayati
\end{abstract}

[email korespondensi: srimaria13p1@yahoo.com]

\begin{abstract}
Feedback Seeking Behavior of Undergraduate Students in the Learning Process at the Faculty of Medicine, Malahayati University, Class of 2020. Since 2008 until now the learning process at the Faculty of Medicine at Malahayati University has implemented a Competency-Based Curriculum (CBC) in accordance with the Competency Standards for Indonesian Doctors. So that students are required to apply the ability of Self Directed Learning (SDL) through the Student Centered and Problem Based strategic approaches. In order to achieve maximum learning objectives, feedback is needed by students. The aim of this research is describe the behavior of seeking feedback from the first batch of undergraduate students in the learning process at the Faculty of Medicine, Malahayati University, batch 2020. A quantitative research with descriptive methods. The sample used in this study were medical students of Class 2020 at the Faculty of Medicine, Malahayati University, Bandar Lampung. Measuring tool uses a questionnaire of feedback seeking behavior that has been tested for validity \& reliability. From 121 respondents, most of the distribution of feedback seeking behavior was in a good category of 68 respondents $(56.2 \%)$. The feedback seeking behavior from the first batch of students in class of 2020 are mostly good. Based on the good category is the process category, while the least is the aspect category.
\end{abstract}

Keywords: Feedback, Students, Learning

\begin{abstract}
Abstrak: Perilaku Mencari Umpan Balik Mahasiswa Tahap Sarjana Angkatan Pertama Dalam Proses Pembelajaran Di Fakultas Kedokteran Universitas Malahayati Angkatan 2020. Sejak tahun 2008 sampai saat ini proses pembelajaran di Fakultas Kedokteran Universitas Malahayati telah menerapkan Kurikulum Berbasis Kompetensi (KBK) sesuai dengan Standar Kompetensi Dokter Indonesia. Sehingga peserta didik dituntut untuk menerapkan kemampuan Self Directed Learning (SDL) melalui pendekatan strategi Student Centered dan Problem Based. Agar dapat mencapai tujuan pembelajaran yang maksimal, maka diperlukan umpan balik oleh mahasiswa. Tujuan dari penelitian adalah untuk mengetahui gambaran perilaku mencari umpan balik mahasiswa tahap sarjana angkatan pertama dalam proses pembelajaran di Fakultas Kedokteran Universitas Malahayati angkatan 2020. Jenis penelitian ini adalah kuantitatif dengan metode deskriptif. Sampel yang digunakan pada penelitian ini adalah mahasiswa kedokteran Angkatan 2020 di Fakultas Kedokteran Universitas Malahayati Bandar Lampung. Alat ukur menggunakan kuesioner perilaku mencari umpan balik yang sudah diuji validitas dan reliabilitasnya. Dari 121 responden, sebagian besar didapatkan distribusi perilaku mencari umpan balik adalah kategori baik sebesar 68 responden (56.2\%). Perilaku mencari umpan balik mahasiswa angkatan pertama (2020) sebagian besar sudah baik. Berdasarkan kategori yang
\end{abstract}


sudah baik adalah kategori proses sedangkan yang kurang baik adalah kategori aspek.

Kata Kunci : Umpan Balik, Mahasiswa, Pembelajaran

\section{PENDAHULUAN}

Proses pembelajaran merupakan suatu rangkaian aktivitas belajar mengajar yakni terdapat peserta didik dengan staf pengajar yang berperan untuk meningkatkan pengetahuan mahasiswa pendidikan kedokteran. Proses pembelajaran pendidikan kedokteran selalu mengalami perubahan dari masa ke masa. Konsil Kedokteran Indonesia menerapkan kurikulum berbasis kompetensi melalui pendekatan SPICES (student centered, problem based, integrated, community based, elective, systematic) guna mencapai kesejahteraan umat manusia (Sari, Lisiswanti, dan Oktaria, 2016).

Sejak tahun 2008 sampai saat ini proses pembelajaran di Fakultas Kedokteran Universitas Malahayati telah menerapkan Kurikulum Berbasis Kompetensi (KBK) sesuai dengan Standar Kompetensi Dokter Indonesia (Lestari, Mandala, dan Restu, 2018). Sehingga peserta didik dituntut untuk menerapkan kemampuan Self Directed Learning (SDL) melalui pendekatan strategi Student Centered dan Problem Based (Artini dkk, 2019). Problem Based Learning (PBL) merupakan suatu kurikulum baru yang diaplikasikan pada dunia pendidikan kedokteran. Prinsip yang diterapkan dalam Problem Based Learning (PBL) yaitu pembelajaran berkolaboratif. Pembelajaran kolaboratif ini dapat berupa kegiatan skills lab maupun tutorial. Kegiatan skills lab dan tutorial menuntut peserta didik agar dapat memperbarui pengetahuan yang sudah ada dengan pengetahuan baru melalui berinteraksi secara aktif dan memberi umpan balik (Sari, Lisiswanti, dan Oktaria, 2016).

Umpan balik adalah bagian penting dalam proses pembelajaran yang dapat meningkatkan pencapaian kompetensi mahasiswa. Menurut Hattie dan Timperley (2007) umpan balik sangat memberikan pengaruh terhadap proses pembelajaran dan prestasi, tetapi pengaruhnya bisa positif atau negatif. Sementara menurut Sari (2016) sebagian umpan balik bisa memberi pengaruh buruk dalam proses pembelajaran sehingga dampaknya pembelajaran bisa terhambat. Oleh karena itu tidak semua umpan balik memberikan efek yang baik.

Menurut penelitian yang pernah dilakukan oleh Hattie dalam Sari (2016) yang menganalisis lebih dari 500 studi meta-analisis untuk meneliti aspekaspek yang menentukan pencapaian pendidikan. Terdapat 180 ribu studi dengan peserta kurang lebih 20 hingga 30 juta siswa yang terlibat dalam penelitian ini. 12 studi meta-analisis yang mengamati tentang umpan balik pada situasi kegiatan di kelas, Effect size umpan balik yang didapatkan oleh Hattie yaitu 0.72; umpan balik berpengaruh besar hingga hampir dua kali lipat efek rata-rata semua aktivitas pembelajaran di sekolah adalah 0.40 . Dari hasil penelitian tersebut, kesimpulan yang didapatkan oleh Hettie adalah di antara aspek-aspek yang memberikan pengaruh terhadap pencapaian belajar terdapat umpan balik di antara aspek-aspek tersebut.

Penelitian yang dilakukan oleh Sari (2016) memperoleh hasil yang berbeda yaitu terdapat sebagian umpan balik justru menjatuhkan kinerja, oleh karena itu tidak semua umpan balik berperan penting pada aktivitas pembelajaran. Meskipun sebagian referensi telah membuktikan bahwa umpan balik sangat berperan dalam proses pembelajaran. Akan tetapi umpan balik yang berperan penting mempunyai bagian spesifik khusus yaitu jika berkaitan dengan tugas, tahapan mengerjakan tugas, hingga regulasi diri. Sedangkan umpan balik yang tidak memberikan kegunaan bagi pembelajaran adalah umpan balik yang bersifat individu.

Hasil dari studi serupa juga ditemukan oleh Oktaria dan Soemantri 
(2018) di Fakultas Kedokteran Universitas Lampung dengan subjek penelitian sebanyak empat kelompok mahasiswa yang setiap kelompoknya terdiri dari tujuh hingga 10 mahasiswa dari tahun 2012, 2013 dan 2014 dapat disimpulkan bahwa motivasi mahasiswa untuk mencari umpan balik didasari oleh kemauan untuk mendapatkan informasi yang bermanfaat dan untuk mengontrol kesan orang lain. mahasiswa akan cenderung mencari umpan balik dari seseorang yang memiliki hubungan dekat dengan mereka atau yang kredibilitasnya mereka hargai. Sementara hambatan paling umum bagi mahasiswa untuk mencari umpan balik adalah keengganan dan rasa takut menerima komentar negatif.

Penelitian mengenai persepsi mahasiswa tentang umpan balik di Universitas Malahayati sudah pernah dilaksanakan pada tahun 2019. Dengan subjek penelitian 280 sampel yang terdiri dari anggota angkatan 2016, angkatan 2017, angkatan 2018, serta angkatan 2019. Dari hasil penelitian ini menyimpulkan bahwa frekuensi persepsi mahasiswa terhadap umpan balik untuk seluruh angkatan yang paling banyak adalah kategori baik sebesar 205 responden $(73,2 \%)$. Namun penelitian mengenai perilaku mencari umpan balik mahasiswa dalam proses pembelajaran belum pernah dilakukan sebelumnya (Pratiwi, 2019).

Umpan balik mempunyai kedudukan yang sangat penting pada diskusi Problem Based Learning karena umpan balik dianggap mampu mempengaruhi motivasi dan pendekatan mahasiswa terhadap proses pembelajaran sehingga dapat meningkatkan pencapaian kinerja (Oktaria dan Soemantri, 2018). Dalam pendidikan kedokteran, pentingnya umpan balik sudah dikenal sejak lama. Kurang lebih sejak 20 tahun yang lalu di semua jenjang pendidikan, tahap sarjana dan pascasarjana, di fase pendidikan sebelum klinik dan di klinik. Umpan balik berperan sentral dalam pendidikan kedokteran dalam mendorong mahasiswa belajar dan menjamin tercapainya standar pendidikan. Ada begitu banyak bukti yang mencatat keuntungan umpan balik yang meningkatkan dan memfasilitasi proses belajar di kedokteran (Wungouw dan Doda, 2012).

Berdasarkan hasil survey yang penulis lakukan melalui aplikasi Google Form pada hari Sabtu tanggal 3 Oktober 2020 untuk melihat perilaku mencari umpan balik pada 10 mahasiswa angkatan 2019 diperoleh hasil empat dari 10 mahasiswa angkatan 2019 tidak berani untuk meminta umpan balik, bahkan sembilan dari 10 mahasiswa merasa khawatir dalam mencari umpan balik. Faktanya delapan dari 10 mahasiswa sudah mengetahui bahwa mencari umpan balik merupakan suatu hal yang penting. Penelitian ini penting dilakukan pada mahasiswa kedokteran tahap sarjana angkatan pertama karena di tahap ini mahasiswa masih menyesuaikan diri dan beradaptasi dari jenjang SMA (Sekolah Menengah Atas) ke jenjang perkuliahan namun penelitian tentang perilaku mencari umpan balik mahasiswa kedokteran tahap sarjana angkatan pertama masih sangat terbatas. Maka, penulis ingin melaksanakan pengkajian dari perilaku mencari umpan balik mahasiswa tahap sarjana angkatan pertama dalam proses pembelajaran di Fakultas Kedokteran Universitas Malahayati.

\section{METODE}

Penelitian ini menggunakan metode deskriptif kuantitatif dan menggunakan data primer kuesioner yang telah diuji validitas dan reliabilitasnya. Penelitian ini dilakukan pada tahun 2021 bertempat di Fakultas Kedokteran Universitas Malahayati Bandar Lampung setelah mendapatkan ethical clearance dari Universitas Malahayati. Populasi dan sampel pada penelitian ini adalah seluruh angkatan 2020 di Fakultas Kedokteran Universitas Malahayati yang berjumlah 121 orang karena penelitian ini menggunakan teknik total sampling. Pada penelitian ini diperlukan beberapa alat yang digunakan untuk mendukung penelitian seperti alat tulis dan kuesioner. 
HASIL

Penelitian ini dilaksanakan di Fakultas Kedokteran Universitas Malahayati Kota Bandar Lampung tahun 2021. Jenis Penelitian ini adalah deskriptif kuantitatif menggunakan total sampling sebanyak 121 sampel yang merupakan seluruh mahasiswa program studi kedokteran angkatan 2020 di Fakultas Kedokteran Universitas Malahayati yang telah memenuhi kriteria inklusi dan eksklusi.

Analisis univariat dalam penelitian ini untuk mengetahui distribusi frekuensi usia, jenis kelamin, dan perilaku mencari umpan balik pada mahasiswa program studi kedokteran angkatan 2020 di Fakultas Kedokteran Universitas Malahayati.

Tabel 1. Distribusi Frekuensi Responden

\begin{tabular}{|c|c|c|}
\hline Variabel & Frekuensi & $\begin{array}{c}\begin{array}{c}\text { Persentase } \\
\%\end{array} \\
\end{array}$ \\
\hline \multicolumn{3}{|l|}{ Umur } \\
\hline 17 Tahun & 9 & $7.4 \%$ \\
\hline 18 Tahun & 66 & $54.5 \%$ \\
\hline 19 Tahun & 36 & $29.8 \%$ \\
\hline 20 Tahun & 9 & $7.4 \%$ \\
\hline 21 Tahun & 1 & $0.8 \%$ \\
\hline Jumlah & 121 & $100 \%$ \\
\hline \multicolumn{3}{|l|}{ Jenis Kelamin } \\
\hline Perempuan & 84 & $69.4 \%$ \\
\hline Laki-Laki & 37 & $30.6 \%$ \\
\hline Jumlah & 121 & $100 \%$ \\
\hline \multicolumn{3}{|l|}{ Perilaku Mencari Umpan Balik } \\
\hline Tidak baik (24 - 39) & 53 & $43.8 \%$ \\
\hline Baik $(40-50)$ & 68 & $56.2 \%$ \\
\hline Jumlah & 121 & $100 \%$ \\
\hline
\end{tabular}

Berdasarkan tabel 1 diatas hasil 84 responden (69,4\%). Dari menunjukkan bahwa responden keseluruhan responden, distribusi terbanyak berusia 18 tahun yang perilaku mencari umpan balik adalah berjumlah 66 orang $(54,5 \%)$. Lalu, kategori baik sebesar 68 responden jumlah responden sebagian besar (56.2\%).

berjenis kelamin Perempuan berjumlah

Tabel 2. Distribusi Perilaku Mencari Umpan Balik Berdasarkan Analisis Kategori yang Sudah Baik

\begin{tabular}{llccc}
\hline \multicolumn{1}{c}{ PERNYATAAN } & $\begin{array}{l}\text { UF } \\
\text { /F }\end{array}$ & YA & PERSENTASE & KATEGORI \\
\hline $\begin{array}{l}\text { Saya tidak pernah bersemangat ketika } \\
\text { berdiskusi untuk mendapat umpan balik } \\
\text { dari dosen }\end{array}$ & UF & 10 & $8 \%$ & Proses \\
\hline $\begin{array}{l}\text { Saya percaya dengan adanya umpan } \\
\text { balik dapat memperbaiki pekerjaan } \\
\text { saya }\end{array}$ & $\mathbf{F}$ & $\mathbf{1 1 7}$ & $\mathbf{9 7 \%}$ & Proses \\
$\begin{array}{l}\text { Dosen memberikan umpan balik } \\
\text { sesuai topik yang didiskusikan }\end{array}$ & $\mathbf{F}$ & $\mathbf{1 1 9}$ & $\mathbf{9 8 \%}$ & Aspek \\
$\begin{array}{l}\text { Saya sebagai mahasiswa kedokteran } \\
\text { tidak menginginkan umpan balik dari } \\
\text { siapapun }\end{array}$ & & 10 & $8 \%$ & Elemen \\
\begin{tabular}{l} 
Setelah mendapatkan umpan balik dari \\
\hline
\end{tabular} & F & 115 & $95 \%$ & Elemen \\
\hline
\end{tabular}


dosen, saya merasa ada kemajuan

dalam performa saya

Berdasarkan data pada tabel 2, dengan pernyataan "Saya percaya terlihat bahwa kategori yang sudah baik dengan adanya umpan balik dapat ditunjukan dari skor pernyataan yang memperbaiki pekerjaan saya" dengan dijawab untuk favorable skor yang 117 responden (97\%) menjawab "ya". paling tinggi. Sedangkan untuk $\mathrm{Hal}$ ini menunjukan kategori proses unfavorable skor paling rendah. sudah cukup baik dilakukan sebagai Didapatkan pada kategori proses kategori perilaku mencari umpan balik.

Tabel 3. Distribusi Perilaku Mencari Umpan Balik Berdasarkan Analisis Kategori yang Masih Kurang Baik

\begin{tabular}{|c|c|c|c|c|}
\hline PERNYATAAN & $\begin{array}{l}\text { UF/ } \\
\text { F }\end{array}$ & YA & PERSENTASE & KATEGORI \\
\hline $\begin{array}{l}\text { Dosen menggunakan bahasa yang } \\
\text { sulit saya pahami sehingga saya } \\
\text { sering salah paham dengan umpan } \\
\text { balik yang diberikan }\end{array}$ & UF & 55 & $46 \%$ & Elemen \\
\hline $\begin{array}{l}\text { Tanpa berupaya secara keras } \\
\text { saya bisa meminta pendapat } \\
\text { orang lain }\end{array}$ & UF & 73 & $60 \%$ & Aspek \\
\hline $\begin{array}{l}\text { Saya akan melihat dan } \\
\text { melakukan yang dilakukan dosen } \\
\text { tetapi tidak untuk umpan balik }\end{array}$ & UF & 66 & $55 \%$ & Aspek \\
\hline $\begin{array}{l}\text { Saya aktif dalam pembelajaran } \\
\text { tetapi bukan untuk mendapat umpan } \\
\text { balik }\end{array}$ & UF & 64 & $53 \%$ & Aspek \\
\hline $\begin{array}{l}\text { Saya tidak pernah meminta meminta } \\
\text { umpan balik lebih dari dua kali }\end{array}$ & UF & 62 & $51 \%$ & Aspek \\
\hline
\end{tabular}

Berdasarkan data pada tabel 3, terlihat bahwa kategori yang masih kurang baik dalam hal frekuensi perilaku mencari umpan balik ditunjukan dari skor pernyataan yang dijawab untuk unfavorable yang mendapatkan skor paling tinggi. Didapatkan pada kategori aspek dengan pernyataan "Tanpa berupaya secara keras saya bisa meminta pendapat orang lain" dengan 73 responden (60\%) menjawab "ya" serta pada pernyataan "Saya akan melihat dan melakukan yang dilakukan dosen tetapi tidak untuk umpan balik" sebesar 66 responden (55\%) menjawab "ya". Hal ini menunjukan kategori aspek masih kurang baik dilakukan sebagai kategori perilaku mencari umpan balik.

Tabel 4. Nilai Kuesioner Responden

\begin{tabular}{cccc}
\hline Responden & N & Median & (Min - Max) \\
\hline Laki-laki & 37 & 40 & $25-50$ \\
Perempuan & 84 & 40 & $24-50$ \\
Total & $\mathbf{1 2 1}$ & $\mathbf{4 0}$ & $\mathbf{2 4 - 5 0}$ \\
\hline
\end{tabular}


Dari tabel 4 di atas menunjukkan nilai tertinggi responden perempuan adalah 50 dan terendah adalah 24 dan didapatkan nilai median seluruh responden adalah 40 .

\section{PEMBAHASAN}

\section{Distribusi Frekuensi Berdasarkan Usia}

Pada tabel 1 distribusi frekuensi berdasarkan usia menunjukan bahwa responden dengan karakteristik responden berdasarkan usia dari 121 mahasiswa terdapat umur 17 tahun sebanyak 9 responden $(7,4 \%)$, sedangkan mahasiswa dengan usia 18 tahun sebanyak 66 responden $(54,5 \%)$, sedangkan mahasiswa yang berusia 19 tahun sebanyak 36 mahasiswa $(29,8 \%)$, dan yang berusia 20 tahun sebanyak 9 mahasiswa $(7,4 \%)$, serta mahasiswa yang berusia 21 tahun sebanyak 1 mahasiswa $(0.8 \%)$. Masa dewasa biasanya dimulai sejak seseorang berusia 18 tahun. Pada masa ini, seseorang akan mengalami suatu perubahan fisik dan psikologis tertentu bersamaan dengan masalahmasalah penyesuaian diri dan harapan-harapan terhadap suatu perubahan (Maludya, Adelina, dan Hidayat, 2018). Hal ini sejalan dengan penelitian serupa sebelumnya yang dilakukan oleh Dyah Ayu Pratiwi pada tahun 2019 yang menunjukan bahwa pada penelitiannya usia responden berkisar antara 17 sampai dengan 21 tahun. Karakteristik individu seperti usia dapat mempengaruhi interpretasi persepsi seseorang, sehingga setiap orang yang usianya berbeda mempunyai persepsi yang berbeda terhadap suatu objek atau stimulus. Usia memberikan pengaruh terhadap daya tangkap dan pola pikir seseorang (Fitriana, Pratiwi, dan Sutanto, 2015). Sehingga dapat disimpulkan bahwa mahasiswa tahap awal sarjana paling banyak adalah usia 18 tahun.

\section{Distribusi Frekuensi Berdasarkan Jenis Kelamin}

Pada tabel 1 distribusi frekuensi berdasarkan jenis kelamin dari 121 mahasiswa terdapat responden dengan karakteristik perempuan berjumlah 84 mahasiswi $(69,4 \%)$ dan responden berjenis kelamin laki-laki berjumlah 37 mahasiswa (30,6\%). $\mathrm{Hal}$ ini sejalan dengan hasil penelitian Fitriana, Pratiwi dan Sutanto pada tahun 2015 yang menyatakan bahwa responden berjenis kelamin perempuan berjumlah 130 mahasiswi $(86,7 \%)$ dan responden berjenis kelamin laki-laki berjumlah 20 mahasiswa (13,3\%). Hasil ini juga sejalan dengan penelitian Akbar dan Widjaja (2019) yang menunjukan bahwa responden perempuan 66 mahasiswi $(61,1 \%)$ dan responden laki-laki berjumlah 42 mahasiswa $(38,9 \%)$. Jenis kelamin merupakan salah satu faktor yang mempengaruhi perilaku seseorang dimana terdapat perbedaan perilaku antara laki-laki dan perempuan. Perilaku laki-laki atas dasar pertimbangan rasional atau akal sedangkan pada perempuan atas dasar emosional (Febriyanto, 2016). Sehingga dapat disimpulkan bahwa jenis kelamin dapat mempengaruhi perilaku seseorang dimana terdapat banyak perbedaan antara laki-laki dan perempuan.

\section{Distribusi Frekuensi Berdasarkan Perilaku Mencari Umpan Balik}

Dari tabel 1 terlihat bahwa dari keseluruhan responden, didapatkan hasil perilaku mencari umpan balik mahasiswa menduduki kategori baik dengan jumlah sebesar 68 responden $(56,2 \%)$ dan yang memiliki kategori tidak baik sebesar 53 responden $(43,8 \%)$. Perilaku mencari umpan balik dapat dikatakan baik apabila dalam pelaksanaannya sesuai dengan tahapan umpan balik yang meliputi proses, elemen, serta aspek - aspek penting yang merupakan kunci dari umpan balik sedangkan perilaku mencari umpan balik yang tidak baik dapat dipengaruhi oleh faktor kurangnya kemauan mahasiswa untuk mendapatkan informasi 
mengenai performanya. Perilaku mencari umpan balik yang tidak baik dapat juga dipengaruhi oleh dosen yang memberikan umpan balik dengan bahasa yang sulit dipahami oleh mahasiswa sehingga sering salah dalam memahami maksud dari umpan balik yang diberikan. Akibatnya mahasiswa enggan untuk meminta umpan balik pada kegiatan selanjutnya. Respon mahasiswa sangat beragam mulai dari meminta umpan balik hanya dari dosen yang mumpuni saja hingga meminta umpan balik dari teman yang lebih pintar. Sejalan dengan hasil penelitian Oktaria dan Soemantri tahun 2018 dimana mahasiswa akan cenderung mencari umpan balik dari seseorang yang memiliki hubungan dekat dengan mereka atau yang kredibilitasnya mereka hargai. Setelah mendapatkan umpan balik mereka merasa ada kemajuan pada performa nya. Hal ini sejalan dengan teori tujuan dilakukannya pemberian umpan balik adalah untuk kemajuan pembelajar, Oleh karena itu umpan balik tidak hanya bermanfaat bagi pemula tetapi umpan balik sangat bermanfaat bagi pembelajar di berbagai tahap pembelajaran (Sari, 2016). Sebagian besar mahasiswa menunggu waktu yang tepat untuk meminta umpan balik guna menghindari dosen yang memiliki perasaan yang berubah-ubah. Hasil tersebut sesuai dengan teori bahwasannya individu cenderung menunggu sampai target dalam suasana hati yang baik sebelum mendekati nya untuk mendapatkan umpan balik (Crommelinck dan Anseel, 2013).

Sedangkan pada tabel 2 dan 3 terlihat bahwa dari ketiga kategori tersebut didapatkan jumlah terbanyak adalah kategori aspek yang berisi pernyataan favorable "saya percaya dengan adanya umpan balik dapat meningkatkan pekerjaan saya" dengan jumlah responden sebanyak 117 mahasiswa (97\%) mengisi jawaban "ya". Hal ini sejalan dengan penelitian serupa yang mengatakan bahwa perilaku mencari umpan balik meliputi proses yang terdiri dari tiga tahap yaitu proses motivasi, kognisi, dan perilaku (Candra dan Idiastuti, 2019). Ini memberikan pengertian bahwa mahasiswa akan cenderung mudah untuk mengetahui secara spesifik tentang apa kekurangan masing masing individu sehingga mahasiswa mengetahui apa yang harus diperbaiki kedepannya. Menurut Sari (2016) ketika memberikan umpan balik cara penyampaiannya sangat mempengaruhi kemampuan mahasiswa menyadari umpan balik tersebut. Umpan balik harus sejalan dengan kinerja, tujuan dan misi dari pembelajaran secara keseluruhan (Sharma dan Marandure, 2011). Umpan balik yang lebih fokus pada arahan dan solusi merupakan salah satu faktor yang mempengaruhi diterimanya umpan balik oleh mahasiswa (Darungan, Rahayu, dan Claramita, 2016). Pernyataan lainnya yang juga kategori proses yaitu "saya percaya dengan adanya umpan balik dapat memperbaiki pekerjaan saya" dengan jumlah responden 117 mahasiswa (97\%) menjawab "ya". Sama halnya dengan pernyataan dari kategori elemen yaitu "setelah mendapatkan umpan balik dari dosen, saya merasa ada kemajuan dalam performa saya" dengan jumlah responden 115 mahasiswa (95\%) menjawab "ya". Hal ini bersesuaian dengan penelitian sebelumnya yang dilakukan oleh Universitas Sam Ratulangi yaitu umpan balik merupakan suatu hal yang penting untuk meningkatkan pembelajaran mahasiswa. Umpan balik dianggap mampu mempengaruhi motivasi dan pendekatan mahasiswa terhadap proses pembelajaran sehingga dapat meningkatkan pencapaian kinerja (Oktaria dan Soemantri, 2018).

Didapatkan pula pada pernyataan unfavorable di kuesioner dengan jumlah paling sedikit yaitu dari kategori proses dan elemen yang berisi "Saya tidak pernah bersemangat ketika berdiskusi untuk 
mendapat umpan balik dari dosen" serta "Saya sebagai mahasiswa kedokteran tidak menginginkan umpan balik dari siapapun" dengan jumlah responden hanya 10 mahasiswa (8\%) mengisi jawaban "ya". sehingga peneliti menyimpulkan bahwa Sebagian besar responden menginginkan umpan balik dari dosen maupun teman dan bersemangat ketika berdiskusi untuk mendapatkan umpan balik.

Adapula hasil pernyataan dari kategori elemen "dosen menggunakan bahasa yang sulit saya pahami sehingga saya sering salah paham dengan umpan balik yang diberikan" dengan jumlah responden 55 mahasiswa (46\%) menjawab "ya". Mahasiswa baru lebih sering mengalami kesulitan dalam memahami umpan balik yang diberikan, dibanding dengan mahasiswa tingkat kedua atau ketiga (Darungan, Rahayu, dan Claramita, 2016). Cara penyampaian ketika seseorang dosen memberikan umpan balik ternyata sangat mempengaruhi kemampuan mahasiswa untuk menyadari umpan balik tersebut (Sari, 2016).

Hasil pernyataan unfavorable dari kategori aspek "tanpa berupaya secara keras saya bisa meminta pendapat orang lain" dengan jumlah responden 73 mahasiswa (60\%) menjawab "ya". Pernyataan unfavorable lainnya dari kategori aspek "saya akan melihat dan melakukan yang dilakukan dosen tetapi tidak untuk umpan balik" dengan jumlah responden 66 mahasiswa (55\%) menjawab "ya". Pernyataan unfavorable lainnya dari kategori aspek yaitu "saya aktif dalam pembelajaran tetapi bukan untuk mendapat umpan balik" dengan jumlah responden 64 mahasiswa (53\%) menjawab "ya" serta "saya tidak pernah meminta umpan balik lebih dari dua kali" dengan jumlah responden 62 mahasiswa (51\%) menjawab "ya".

Berdasarkan hasil jawaban responden yang beragam maka peneliti menyimpulkan bahwa perilaku mencari umpan balik mahasiswa sebagian besar adalah kategori baik. 68 dari 121 responden menginginkan umpan balik dari dosen maupun teman, namun sebagian kecil dari responden masih ada yang tidak baik dalam mencari umpan balik.

\section{KESIMPULAN}

Berdasarkan hasil penelitian yang telah dilaksanakan di Fakultas Kedokteran Universitas Malahayati provinsi Lampung tahun 2020 dapat disimpulkan bahwasanya frekuensi umur terbanyak pada penelitian ini adalah usia 18 tahun sebanyak 66 responden $(54,5 \%)$ dan frekuensi jenis kelamin terbanyak pada penelitian ini adalah jenis kelamin perempuan berjumlah 84 mahasiswi (69,4\%). Lalu, frekuensi perilaku mencari umpan balik mahasiswa untuk seluruh angkatan yang paling banyak adalah kategori baik sebesar 68 responden (56.2\%). Sementara itu, frekuensi perilaku mencari umpan balik mahasiswa berdasarkan kategori proses, aspek, dan elemen secara keseluruhan sudah baik. Kategori yang paling banyak adalah proses sebesar 117 responden $(97 \%)$. Sedangkan yang masih harus ditingkatkan lagi adalah kategori aspek sebesar 48 responden (40\%).

\section{SARAN}

Bagi mahasiswa, disarankan untuk dapat meningkatkan keinginan untuk mencari umpan balik dalam pembelajaran agar lebih baik lagi terutama pada kategori aspek yaitu dengan cara berusaha keras untuk mendapatkan umpan balik, setiap melakukan sesuatu tetap ingin mendapatkan umpan balik, serta melatih kemampuan komunikasi yang baik. Selain itu, peneliti lain dapat melakukan penelitian serupa di waktu dan tempat yang berbeda untuk mengevaluasi lebih dalam lagi mengenai proses perilaku mencari umpan balik yang meliputi pemberian dan penerimaan umpan balik karena penting bagi kemajuan pembelajaran 
mahasiswa. Peneliti lain juga dapat melakukan penelitian serupa dengan jenis penelitian kualitatif (wawancara secara langsung). Peneliti dapat juga meneliti tentang hubungan motivasi dengan upaya mencari umpan balik. Lalu, Institusi dapat mengadakan seminar atau kuliah umum tentang pentingnya mencari umpan balik dalam proses pembelajaran serta mengevaluasi proses pemberian umpan balik oleh tutor secara berkala melalui alat yang dapat diukur seperti kuesioner dan disebarkan kepada mahasiswa.

\section{DAFTAR PUSTAKA}

Akbar, R., \& Widjaja, Y. (2019). Efektivitas diskusi problem based learning di Fakultas Kedokteran Universitas Tarumanagara. Tarumanegara Medical Journal 2(1): 160-166.

Artini, I., Hasbi, N.F., Putri, A.M., Maria, S., Utami, D., Setiawati, O.R., dkk. (2019). Buku Modul Kemampuan Dasar Umum Generic Skill. Bandar Lampung: Universitas Malahayati.

Candra, S. A., \& Indiastuti, D. L. (2019). Pengaruh Perilaku Mencari Umpan Balik Terhadap Kinerja Dengan Variabel Moderasi Keadilan Prosedural. Jurnal Ekonomi, Bisnis, Dan Akuntansi (JEBA) 21(1).

Crommelinck, M., \& Anseel, F. (2013). Understanding and encouraging feedback-seeking behaviour: A literature review. Medical Education 47(3): 232-241. https://doi.org/10.1111/medu.120 75

Darungan, T. S., Rahayu, G. R., \& Claramita, M. (2016). Evaluasi Proses Pemberian Feedback di Tutorial Problem-Based Learning di Fakultas Kedokteran. Jurnal Pendidikan Kedokteran Indonesia 5(2): $\quad 88-100$. https://doi.org/10.22146/jpki.2532 0 .

Febriyanto, M.A.B. (2016). Hubungan Antara Pengetahuan dan Sikap dengan Perilaku Konsumsi Jajanan Sehat di MI Sulaimaniyah Mojoagung Jombang. [Skripsi]. Surabaya: Universitas Airlangga.
Fitriana, Y., Pratiwi, K., Sutanto, A. V. (2015). Faktor-faktor yang berhubungan dengan perilaku orang tua dalam melakukan kekerasan verbal terhadap anak usia pra-sekolah. Jurnal Psikologi 14(1).

Hattie, J., \& Timperley, H. (2007). The power of feedback. Review of Educational Research 77(1): 81112.

https://doi.org/10.3102/00346543 0298487.

Lestari, S. M. P., Mandala, Z., Restu, N.B. (2018). Hubungan Persepsi Lingkungan Pembelajaran Dengan Strategi Pembelajaran Pada Mahasiswa Fakultas Kedokteran Universitas Malahayati Angkatan 2017. Jurnal Ilmu Kedokteran Dan Kesehatan 5(2): 107-116.

Maulidya, F., Adelina, M., Hidayat, A.F. (2018) Periodisasi Perkembangan Dewasa. [Skripsi]. Sidoarjo: Universitas Muhamadiyah Sidoarjo.

Oktaria, D., \& Soemantri, D. (2018). Undergraduate medical students' perceptions on feedback-seeking behaviour. Malaysian Journal of Medical Sciences 25(1): 75-83. https://doi.org/10.21315/mjms201 8.25.1.9

Pratiwi, D.A. (2020). Persepsi Mahasiswa Tentang Umpan Balik Dalam Proses Pembelajaran Kurikulum Berbasis Kompetensi di Fakultas Kedokteran Universitas Malahayati Bandar Lampung Tahun 2019. [Skripsi]. Bandar Lampung: Universitas Malahayati.

Sari, D. P. (2016). Meningkatkan Efektivitas Umpan Balik dalam Pendidikan Klinik. Jurnal Kedokteran Unram 5(2): 31-38.

Sari, M. I., Lisiswanti, R., Oktaria, D., Kedokteran, B. P., Kedokteran, F., \& Lampung, U. (2016). Learning in Medical Education : Introduction for New Medical Students. Jk Unila 1: 399-403.

Sharma, D \& Marandure, D. (2011). Creating Value Through the Strategic Use of Feedback. SSRN Electronic Journal. 
Wungouw, H. I. S. (2012). Peran Umpan Balik Bagi Mahasiswa Kedokteran. Jurnal Pendidikan dan Kedokteran Indonesia 1(3), 151158.

https://doi.org/10.22146/jpki.2509

9. 